\title{
Prediction of Obsessive-compulsive Symptoms Based on Negative Affect, Rumination, and Dispositional Mindfulness
}

\author{
Afsaneh Mahmoudi \\ M. A. in psychology, Department of psychology, Faculty of Education and Psychology, \\ University of Tabriz, Tabriz, Iran \\ Rasoul Heshmati \\ Associate Professor, Department of psychology, Faculty of Education and Psychology, \\ University of Tabriz, Tabriz, Iran \\ * Corresponding author: psy.heshmati@gmail.com \\ Majid Mahmoud Alilou \\ Professor, Department of psychology, Faculty of Education and Psychology \\ University of Tabriz, Tabriz, Iran
}

\begin{abstract}
Obsessive-compulsive symptoms could be an important background for clinical disorder of OCD. The role of negative affect, rumination, and dispositional mindfulness has not been investigated in previous researches. Therefore, the purpose of this study was to study the relationship among negative affect, rumination, dispositional mindfulness with obsessive-compulsive symptoms. In a descriptive-correlational and crosses- sectional study, 283 students from University of Tabriz have selected by available sampling method during April through May 2017.Maudsley OCD inventory, Positive affect and negative affect scale (PANAS), Five Facet Mindfulness Questionnaire (FFMQ) and Rumination Scale of the Response Styles Questionnaire were used for collecting the data. Data were analyzed using Pearson correlation and multiple Regressions tests. The results showed that correlation between obsessive-compulsive symptoms and dispositional mindfulness was negative and significant, correlation between obsessive-compulsive symptoms and negative affect was positive and significant and correlation between obsessive-compulsive symptoms and rumination was significant. Also, negative affect, rumination, and dispositional mindfulness did able to predict the obsessivecompulsive symptoms. Dispositional mindfulness, negative affect, and rumination are the important determinants of obsessive-compulsive symptoms.
\end{abstract}

Keywords: Obsessive-compulsive symptoms, Rumination, Dispositional mindfulness, Negative affect.

Received 2 May 2019/Accepted 12 December 2019 @JEHCP All rights reserved 


\section{Introduction}

Obsessive - compulsive disorder (OCD) in DSM-5 has been placed in a separate diagnosis under the title of "Obsessive-Compulsive disorders and related disorders" in seventh category of classification that of the most important disorders of this category it could mention to OCD, trichotillomania, body dysmorphic disorder, hoarding disorder and excoriation (skin picking).The prevalence of OCD in general population is estimated 2 to 3 percent and some researchers estimated that the rate of prevalence of this disorder among outpatient of psychiatric clinics it reaches to 10 percent (Julien, O'Connor, \& Aardema, 2007; Sadock \& Sadock, 20II). Also, this disorder has been found in 5 to 4 percent of adult patients treated in outpatient psychiatric complexes. Based on this, OCD is the fourth prevalent disorder after phobias, abuse and depression (Purdon \& Clark, 1999).

Success and unsuccessful in controlling unwanted thoughts could be related to some variables. For example, accepting a confounding thought and in other words mindful confrontation, will eliminate depression and vigilance. Similarly, accepting non pragmatism could decrease need to worry about finding perfectionist and complete solutions(Leahy, 2007). "Being mindful" means observinging unwanted thoughts, feelings, and bodily senses without judging or attaching to them or trying to stop or change them. In fact, mindfulness could be defined as attention in special and purposeful way at the present time and without judgment (Moore \& Malinowski, 2009). Several definitions of dispositional mindfulness reflect three basic features. (a) attention and awareness focused on present time, (b) purpose that adds motivational component to the attention and behavior, (c) attitude that shows the way of person's attention are the position that the person has while attending like interest, curiosity, non-judgment, acceptance and being accountable (Duncan, Miller, Wampold, \& Hubble, 2010). Those who show higher level of dispositional mindfulness show less negative automatic thoughts and believe that they are able to get rid of such thoughts (Frewen, Evans, Maraj, Dozois, \& Partridge, 2008).

The component of non-judgment experience of dispositional mindfulness has negative correlation with thought suppression (Emanuel, 2009). This component points to taking a non appraisal position toward private experiences (like cognitive biases, beliefs and assumptions in OCD) (Kabat-Zinn, 2003) and help the person to experience the emotions as they occur without evaluating them as good or bad (Emanuel, 2009). 
Rumination is defined as recurring and resistant thought around a usual issue. These thoughts enter the awareness unconsciously and distract the attention from the intended issues and present purposes (Joormann, 2006). Many studies showed that rumination does not just implicate to depression, but rumination relates both with depressive and anxiety symptoms (Fresco, Frankel, Mennin, Turk, \& Heimberg, 2002; Muller \& Roberts, 2005; Muris, Roelofs, Meesters, \& Boomsma, 2004; Segerstrom, Tsao, Alden, \& Craske, 2000). The patients, who have rumination, consider it a method that uses to obtain insight toward their own problem and through that concentrate on their inner, problematic situation and their feelings (Smith \& Alloy, 2009). In words, they think that rumination is helpful and help them in solving their problems, but response to the problems through rumination is along with more tension and problems. Of the main features related to rumination are: negative affect and depressive symptoms, negative oriented thought, weak problem solving, damaged motivation and advantageous behaviors inhibition, damaged concentration, and increased stress and special problems (for example threatening physical health, damaged social relations, malfunctioned emotional adaptation and stress (Nolen-Hoeksema, Morrow, \& Fredrickson, 1993)

One of the other variables related to $O C D$ is negative affect. In recent researches, the psychological construction of negative affect (NA) has been mentioned, negative affect refers to the person's interest to experience negative feelings like anger, hate, anxiety in different situations (Pedersen \& Denollet, 2003). Pressman \& Cohen consider negative affect including anxiety and depression while know positive affection including happiness and joy (Pressman \& Cohen, 2005). Regarding the nature, positive and negative affect whether as state or trait are two relatively independent and distinct phenomena. Those people with high positive affect have high spirituality and are energetic.

Research evidences indicate the relationship between positive affect and making social relations of helping behaviors, concentration, focus and high ability to make decision. And in contrast negative affect relates with mental complains, law coping abilities with tension, stress and anxiety (Spindler, Denollet, Kruse, \& Pedersen, 2009). Abramowitz, Whiteside, Lyman and Kalsy (2003) showed that negative affect acts as mediating variable of the relation between fusion of thought action and OCD and negative affect in OCD groups was than control group (Abramowitz, Whiteside, Lynam, \& Kalsy, 2003). 
Based on the findings of the previous researchers it could be said that there are wide spread studies that have examined $O C D$, the factors influencing on it, and also treatment interventions influencing on it, but there are less research that have examined personality traits (e.g. Key, Rowa, Bieling, McCabe, and Pawluk 2017; Didonna and et al 2019; Landmann, Cludius, Tuschen-CaffierMoritz, \& Külz 2019). Obsessive-compulsive symptoms is not considered as a disorder, but is a basic problem and personality difficulty. The present study deals with the role of dispositional mindfulness, negative affect, and rumination as main predictors of obsessive-compulsive symptoms. Based on this, the purpose of this study is to examine obsessive-compulsive symptoms in normal people based on negative affect, dispositional mindfulness and rumination.

\section{Methods}

\section{Respondents}

The present study is of correlational-descriptive and retrospective and non-experimental are regarding the way of data collection, but regarding purposes, it is of basic research in which the relation among criterion variable and predictor variables are being examined. The statistical population of this research included all the students of University of Tabriz who were studying during the educational year of April through May 2017. Of the statistical population 283 students have been selected by available sampling method. Of all participants, $44 \%$ were male and $56 \%$ were female. Regarding that the studied population is wide spread and the list of all the members is not on hand, so in order to select the sample, the available method was used. Such that it has been referred to the faculties of Tabriz University and asked those students interested in participating in the research to answer the questionnaires. They were assured that all questionnaires are anonymous, and participation is voluntary. Informed consent has been signed by all respondents.

\section{Instruments}

A) Maudsley OCD inventory: This inventory is composed of 30 items that answering to them is done by two options of correct and incorrect and has been designed for measuring OCD symptoms (e.g., "I am often late because I can't seem to get through everything on time"). This inventory includes 5 sub scales (examination, washing, doubt examination, slowness, and mental rumination). To score this inventory, those answers that are consistent with the key get scare I and the inconsistent ones 
get score 0. The maximum score obtained in each 5 scale is respectively 3-9-II-7- Strenberg \& Brntza (1990) reported reliability coefficient of the test by retest method as 0.89 (M, 20I3).

B) Positive affect and negative affect scale (PANAS): This scale is self- report, 20item scale and has been designed to measure two dimensions of affect i.e. negative affect (e.g., "Hostile") and positive affect (e.g., " Active") (Watson, Clark, \& Carey, 1988). Each subscale has 10 items. The items one rank on a five point scale $(0=$ not at all, to $5=$ very much) by the subject. PANAS is a self report scale and by changing the direction, it can measure both its state part and trait part and if the time framework refers to the present week, state part of affect is being measured and longer time is being considered, trait part is being measured. The score range for each subscale is 10 to 50 . In the present study, the subjects were answering the items based on their general method and trait part. PANAS has optimal psychometric properties. Coefficients of internal consistency (alpha) for the subscale of positive affect is 0.88 and for negative affect is 0.87 the test-retest reliability with 8 week interval for positive affect, it has been reported as 0.98 and for negative affect, it has been reported as 0.71 (Watson et al., 1988) . Regarding validity, correlations among these subscales with some measuring instruments that measure the constructs related to these affects like anxiety and depression has been also reported as high rate .for example, correlation of negative affect subscale with Beck depression inventory $(\mathrm{BDI})$ is 0.58 and correlation of the subscales of positive affect with this questionnaire is -0.34 and also correlation of subscale of negative affect with obvious anxiety scale in the questionnaire of obvious - hidden anxiety is $0.5 \mathrm{I}$ and correlation of subscale of positive affect with obvious anxiety scale is reported as 0.35 (Watson et al., 1988).

C) Rumination Scale of the Response Styles Questionnaire: This scale that is self-report scale is designed by Nolen-Hoeksema, (1991). Rumination Scale of the Response Styles Questionnaire is a scale with 22 item (e.g., " go away by yourself and think about why you feel this way") which items are scored in the scale of 4 point prom I (almost never) to 4 (almost ever) (Nolen-Hoeksema et al., I993). In this test the range of scores are from 22 to 88 . Total score of rumination is calculated by summing all the items. In addition, the scale is composed of three subscales of distraction (items of $1,2,3,4$, $6,8,9,14,14,18,19,22$ ), reflection (items of $11,1,12,20,21$ ) and thinking (items of $13,15,16$, $5,10)$. Using Cronbach's alpha, that is reported as 0.92 in this research, it has been showed that this scale has high internal reliability, its inter-class correlation has been measured 5 times and it has been reported as 0.75 . Based on empirical evidences, this scale has high internal reliability. 
Coefficient of Cronbach's alpha is in a range between 0.88 to 0.92 . Several researches showed that retest correlation for this scale is 0.67 (Papageorgiou \& Wells, 2004).

D) Five Facet Mindfulness Questionnaire (FFMQ): the mindfulness trait was evaluated using the Five Facets Mindfulness Questionnaire (FFMQ) Baer et al., (Baer, 2003; Baer, Smith, Hopkins, Krietemeyer, \& Toney, 2006; Baer et al., 2008). The FFMQ contains 39 items (e.g., "When l'm walking, I deliberately notice the sensations of my body moving") measuring 5 different subscales: Observing, Describing, Acting with Awareness, Non-judging and Non-reacting. Observing means the ability to pay attention to internal and external stimuli; Describing refers to the ability to verbally label internal experiences; Acting with Awareness is related to attending to one's present activities; Non-judging is linked to a non-evaluative stance of one's own emotions and thoughts; Non-reacting refers to the tendency to allow one's own feelings and thoughts to pass by without getting caught up in them.

\section{Data analysis}

The data was analyzed by applying SPSS 22 software. Questionnaire data were checked for missing items. Data were presented by mean (SD), Min-Max and frequency (\%) for quantitative and qualitative variables. Pearson correlations and multiple regression tests assessed the relationships between obsessive-compulsive symptoms with negative affect, rumination, and dispositional mindfulness.

\section{Results}

Mean of the number of 283 people from sample in negative affect equals 12.62 and also its SD, equals 3.69 , variance is 13.68 , mean of positive affect is 18.34 , median is 18 and mode is 19 . Also SD is 3.08 , variance is $9.5 \mathrm{I}$. In rumination is 54.34 , also $S D$ is 8.10 , variance is 65.76 , in $O C D$ is 54.34, SD is 8.10 and variance is 65.76 , in dispositional mindfulness is 122.38 also SD is 11.38 and Variance 128.72.

In table $\mathrm{I}$, it is observed that Pearson correlation among negative affect with positive affect and dispositional mindfulness, correlation among positive affect with rumination and obsessivecompulsive symptoms and correlation among rumination and dispositional mindfulness and 
obsessive-compulsive symptoms with dispositional mindfulness are negative and significant. Also, correlation between rumination and negative affect, obsessive-compulsive symptoms with negative affect, dispositional mindfulness with positive affect and correlation of rumination with obsessivecompulsive symptoms were positive and significant.

Table I

Pearson correlation of research variables

\begin{tabular}{cccccc}
\hline Variables & $\begin{array}{c}\text { negative } \\
\text { affect }\end{array}$ & $\begin{array}{c}\text { Positive } \\
\text { affect }\end{array}$ & Rumination & $\begin{array}{c}\text { obsessive- } \\
\text { compulsive } \\
\text { symptoms }\end{array}$ & $\begin{array}{c}\text { Dispositional } \\
\text { mindfulness }\end{array}$ \\
\hline $\begin{array}{c}\text { negative affect } \\
\begin{array}{c}\text { Positive affection } \\
\text { rumination }\end{array}\end{array}$ & $\begin{array}{c}-0.350^{* *} \\
0.368^{* *}\end{array}$ & $-0.311^{* *}$ & --- & & \\
obsessive- & $0.184^{* *}$ & -0.026 & $0.255^{* *}$ & --- & \\
compulsive & & & & & \\
symptoms & & & $-0.46 I^{* *}$ & $-0.230^{* *}$ & --- \\
$\begin{array}{c}\text { Dispositional } \\
\text { mindfulness }\end{array}$ & $-0.002^{* *}$ & $0.383^{* *}$ & & & \\
\hline
\end{tabular}

The results of table 2 shows that multiple correlational coefficient equals 0.230 and its square is 0.053 that is called coefficient of determination and it is the rate of common variance. Coefficient of determination and regression coefficient is significant in the level of 0.01 that shows that about $5 \%$ of changes in obsessive-compulsive symptoms are predictable by dispositional mindfulness.

Table 2

Results of regression analysis of predicting obsessive-compulsive symptoms by dispositional mindfulness

\begin{tabular}{cccccc}
\hline Variable & $\begin{array}{c}\text { Regression } \\
\text { coefficient }\end{array}$ & SD & Beta & $\mathrm{T}$ & Sig \\
\hline $\begin{array}{c}\text { Fixed value } \\
\text { Dispositional } \\
\text { mindfulness }\end{array}$ & 25.704 & 2.636 & --- & 9.752 & $\mathrm{P}<0.0 \mathrm{I}$ \\
\hline $\mathrm{R}=0.030$ & -0.085 & 0.021 & -0.230 & -3.970 & $\mathrm{P}<0.0 \mathrm{I}$ \\
\hline
\end{tabular}

The results of table 3 shows that multiple correlational coefficients is 0.340 and its square is 0.115 that is coefficient of determination and the rate of common variance. Coefficient of determination 
and regression coefficient are significant in the level of $0.0 \mathrm{I}$ that shows around $11 \%$ of changes in the obsessive-compulsive symptoms are predictable by the components of dispositional mindfulness. Of these components, only the Acting with Awareness is significant.

Table 3

Results of Regression Analysis Predicting Obsessive-Compulsive Symptoms by Components of Dispositional Mindfulness

\begin{tabular}{cccccc}
\hline Variable & $\begin{array}{c}\text { Regression } \\
\text { coefficient }\end{array}$ & SD & Beta & $\mathrm{T}$ & Sig \\
\hline Fixed value & 23.040 & 3.150 & --- & 7.314 & $\mathrm{P}<0.0 \mathrm{I}$ \\
Observing & -0.004 & 0.052 & -0.006 & -0.084 & $\mathrm{P}>0.05$ \\
Describing & -0.067 & 0.085 & -0.057 & -0.792 & $\mathrm{P}>0.05$ \\
Acting with & -0.175 & 0.072 & -0.203 & -2.446 & $\mathrm{P}<0.05$ \\
Awareness & & & & & \\
Non-judging & -0.115 & 0.063 & -0.150 & -01.817 & $\mathrm{P}>0.05$ \\
Non-reacting & 0.020 & 0.075 & 0.020 & 0.274 & $\mathrm{P}>0.05$ \\
\hline $\mathrm{R}=0.340$ & $\mathrm{R}^{2}=0.115$ & $\mathrm{~F}=5.163$ & $\mathrm{P}<0.01$ & &
\end{tabular}

The results of table 4 shows that multiple correlational coefficients equals 0.222 and its square are 0.049 that is called coefficient of determination and it is the rate of common variance. Coefficient of determination and regression coefficient is significant in the level of 0.01 that shows that about $5 \%$ of changes in obsessive-compulsive symptoms are predictable by affect. Of these components just the effect of negative affect is significant.

Table 4

Results of Regression Analysis Predicting Obsessive-Compulsive Symptoms by Affection and Its Components

\begin{tabular}{|c|c|c|c|c|c|}
\hline Variable & $\begin{array}{l}\text { Regression } \\
\text { coefficient }\end{array}$ & SD & Beta & $\mathrm{T}$ & Sig \\
\hline Fixed value & 10.495 & 2.055 & --- & 5.108 & $P<0.01$ \\
\hline negative affect & 0.267 & 0.070 & 0.236 & 3.791 & $P<0.01$ \\
\hline Positive affection & 0.077 & 0.085 & 0.057 & 0.913 & $P>0.05$ \\
\hline
\end{tabular}


The results of table 5shows that multiple correlational coefficient equals 0.255 and its square is 0.065 that is called coefficient of determination and it is the rate of common variance. Coefficient of determination and regression coefficient is significant in the level of 0.01 that shows that about $6.5 \%$ of changes in obsessive-compulsive symptoms are predictable by rumination.

Table 5

Results of regression analysis predicting obsessive-compulsive symptoms by rumination

\begin{tabular}{cccccc}
\hline Variable & $\begin{array}{c}\text { Regression } \\
\text { coefficient }\end{array}$ & SD & Beta & $\mathrm{T}$ & Sig \\
\hline Fixed value & 8.195 & 0.868 & --- & 14.048 & $\mathrm{P}<0.0 \mathrm{I}$ \\
rumination & -0.245 & 0.066 & -0.216 & 3.707 & $\mathrm{P}<0.0 \mathrm{I}$ \\
\hline $\mathrm{R}=0.255$ & $\mathrm{R}^{2}=0.065$ & $\mathrm{~F}=19.58$ & $\mathrm{P}<0.0 \mathrm{I}$ & &
\end{tabular}

The results of table 6 shows that multiple correlational coefficient equals $0.35 \mathrm{I}$ and its square is 0.123 that is called coefficient of determination and it is the rate of common variance. Coefficient of determination and regression coefficient is significant in the level of 0.01 that shows that about I2\% of changes in obsessive-compulsive symptoms are predictable by the components of rumination. Of these components distraction has positive effect and reflection is significant with negative effect.

Table 6

Results of regression analysis predicting obsessive-compulsive symptoms by components of rumination

\begin{tabular}{cccccc}
\hline Variable & $\begin{array}{c}\text { Regression } \\
\text { coefficient }\end{array}$ & SD & Beta & $\mathrm{T}$ & Sig \\
\hline Fixed value & $\mathrm{I} 5.720$ & $2.38 \mathrm{I}$ & --- & $6.60 \mathrm{I}$ & $\mathrm{P}<0.0 \mathrm{I}$ \\
distraction & 0.094 & 0.044 & 0.176 & 2.127 & $\mathrm{P}<0.05$ \\
Reflection & -0.244 & 0.095 & -0.200 & $-2.58 \mathrm{I}$ & $\mathrm{P}<0.05$ \\
Thinking & 0.015 & 0.090 & 0.011 & 0.162 & $\mathrm{P}>0.05$ \\
\hline $\mathrm{R}=0.35 \mathrm{I}$ & $\mathrm{R}^{2}=0.123$ & $\mathrm{~F}=13.053$ & $\mathrm{P}<0.01$ & &
\end{tabular}

\section{Discussion}

The results showed that the correlation between obsessive-compulsive symptoms and dispositional mindfulness was negative and significant. This result is consistent with the research by Crow, 
Mackey (2016) who show that the group of OCD were lower in the components of dispositional mindfulness than other groups (Crowe \& McKay, 2016, Bayrami, et al. 2012 ) and also is consistent with the research by Raj and Kumar (2019) that by the purpose of examining the relationship among dimensions of metacognition and dispositional mindfulness with obsessional beliefs and showed that all meta cognition dimensions have positive and significant relation with obsessional beliefs, but of dispositional mindfulness components, description of internal experiences and nonreacting to the internal experiences and non-judgment to the internal experiences have significant and negative relation with obsessional beliefs. This component refers to taking a non- appraisal position toward private experiences (like cognitive biases, beliefs and assumptions in OCD) and help the person to experience the emotions as they happen without evaluating them as good or bad (Emanuel, 2009; Heshmati \& Ghorbani, 2016). Non-reacting to the internal experience refers to this that the person allows his/her feelings and thoughts to come and go without being engaged with them (Baer, 2003; Shaker, Heshmati, \& Rahimi, 20I0).

In the explanation of these findings it could be said that theoretically in OCD negative appraisals of unwanted and confounding thoughts have been identified in three fields that include the importance of thoughts, those appraisals, that refer to the presence and meaning of thoughts that are threatening or are important in the person views, controlling the thoughts, those appraisals that refer to the necessity of controlling thoughts in order to prevent threatening outcomes and responsibility, those appraisals that refer to this issue that if the thoughts continue, the person will be responsible for negative events (Group, 2005). Dispositional mindfulness enable the person to make a basically different relation with internal feelings and external events through making moment to moment awareness and behavior orientation based on rational responsibility instead of automatic reactivity, By applying purposeful higher functions of the mind like attention, awareness, kind attitude, curiosity and empathy, dispositional mindfulness could impose control on emotional reactions effectively through cortex inhibition of limbic system. So, those people with higher level of dispositional mindfulness show less negative automatic thoughts and believe that they are able to get themselves rid of these kinds of thoughts. Of the components of dispositional mindfulness, Acting with Awareness showed significant portion in predicting obsessional beliefs. In this regard, it should be said that Acting with Awareness helps accepting a confounding thought and this by itself eliminates suppression and vigilance that could allow the person to test those belief that has maintained because of internal anxiety states. Similarly, acceptance could decrease need to worry 
for finding complete and perfectionist sic solutions and help the response inflexibility and prevent showing automatic answers (Goradel, Heshmati, \& Alilo. 210; Heshmati, Onari \& Shokrallahi, 2016).

The results of present research showed that correlation between obsessive-compulsive symptoms and negative affect is positive and significant. This result is consistent with KaramiMomeni, Zaki (2013) who reported that there is positive significant relation among negative affect, Alexithymia and its subscales with OCD symptoms (Karami, Momeni, \& Zakiei, 20I3, Heshmati, et.al, 20I4), Also, a negative and significant relation has been found between positive affect and symptoms of OCD and also in a study by Watson, Clark, Kerry the results showed that negative affects have widely positive relationship with all anxiety disorders like phobia, panic, OCD and depressive disorder, but positive affect had just negative significant relation with depression(Watson et al., 1988, Heshmati, et.al, 20II).

In the explanation of this finding it could be said that in human beings positive affect influences on psychological procedures through which we integrate our information and they cause inflexibility in the thoughts. Also, the studies showed that positive affect lead to improvement in creativity and problem solving and make more unusual but rational associations among neutral words in the test of vocabulary association. So positive affect influence a cognitive organization is such that creative answers or new ones are made and it could lead to optimal use of mental resources that in contrast to negative affects lead to inflexible and forced answers (Adair, 2007; Heshmati \& Ahmadkhanloo, 2017; Heshmati, Gharadaghi, Jafari, \& Gholizadehgan, 20I7).

In another explanation on the relationship between negative affect with obsessive-compulsive symptoms, it could be said that based on most of the studies carried out on OCD, This disorder is related with other psychological discarders. Researches, up to now, have shown the relation between OCD with major depression, generalized anxiety, bipolar, tic, ADHD, eating disorder, autism, schizophrenia, schizotype (Pashinian et al., 2006), that depression is of the most prevalent disorders that has overlap with OCD, So, these people tend to depression more than and according to the researches low mood not only lead to serenity of unwanted thoughts, but also lead to increased distress resulted from these thoughts (Sanavio, 1988; Bayrami, 20II). Most of the researches believe that there is overlap between both of those regarding symptoms specially feeling 
guilt, anxiety, doubt about oneself and low self- esteem (Arntz, Voncken, \& Goosen, 2007; Aycicegi, Dinn, Harris, \& Erkmen, 2003).

Also, the results showed that correlation between obsessive-compulsive symptoms and rumination is significant. Consistent with this result in the study of Khosrovi, Mehrabi, AziziMoghadam (2013) by the aim of comparative examination of the components of rumination in patients with depression, $O C D$ and normal people, it was shown that there is significant difference among three groups in total score of rumination and in subscales of reviewing feelings resulted from the problem of self-criticizing and worry about not to solve the problem. The rate of rumination was related with reviewing feelings resulted from problem, worry about not to solve the problem and selfcriticizing in patients with depression and $\mathrm{OCD}$ and normal people. Meanwhile two patient groups had more rumination than normal people.

Rumination is a form of additional cognitions that is seen in people with this disorder and includes permanent mental preoccupation to a thought or issue and have continuous thought about it (Sadock \& Sadock, 20II, Heshmati, 2010). Rumination in patients with OCD includes those thoughts that are reviewed unfinished and lead to disappointment about future and negative appraisal about oneself (Clark, 2004). Increased rumination has been more examined in the context of depression (Nolen-Hoeksema et al., 1993) but in people with OCD, it was seen, too (Fineberg \& Gale, 2005, Heshmati, 2016). Several studies have specially dealt with rumination in OCD that all have reported increased rumination in patients with OCD than normal people (Armstrong, Zald, \& Olatunji, 201I, Heshmati, 2016, Ahmadi, 2010). On the other hand, Derybery \& Reed (2002) indicated that while obsessional thoughts and rumination are different regarding their content, but they could be result from one single susceptibility. One probability to this cognitive susceptibility may be defect in controlling the attention that is a coping strategy which help the person to prevent depressive and anxiety making thoughts and reacting patterns (Derryberry \& Reed, 2002).

\section{Conclusion}

Regarding that the method of this study is correlational one, it is expected that future researches examine the relation of these variables with symptoms or $O C D$ in the framework of controlled case experimental designs to recognize causal relations and reliability of the results for treating the 
symptoms and OCD. Also, considering that the present research was done by focusing on discovering different pathology and the role of multiple components in several obsessions, it is hoped that in the future researches this trend be continued by using the variables present in this study or other variables. In concluding the findings resulted from this study could, in the first place, step on the way of developing basic knowledge in the field of alternative kinds of OCD and its relations with non-clinical psychological variables. Also, dealing with the above discussion could make the professionals more aware toward the position of these patients so that they can confront with this disorder by clear mind. Of other limitations of the study, is lack of special instrument for the compo cat of effective relation with others that of course it has been attempted to use the closest instrument in proportion to the theoretical model. Also, the presence of high number of items and scales was of the limitations of the study. Though it has been tried to use the shorter instrument, but it should consider being tired.

\section{References}

Abramowitz, J., Whiteside, S., Lynam, D., \& Kalsy, S. (2003). Is thought-action fusion specific to obsessive-compulsive disorder?: A mediating role of negative affect. Behaviour research and therapy, 4 I (9), 1069-1079.

Adair, J. E. (2007). The art of creative thinking: How to be innovative and develop great ideas: Kogan Page Publishers.

Ahmadi, M., Abdollahi, M. H., Ramezani, V., \& Heshmati, R. (20l0). The impact of written emotional expression on depressive symptoms and working memory capacity in Iranian students with high depressive symptoms. Procedia-Social and Behavioral Sciences, 5, 1610-1614.

Armstrong, T., Zald, D. H., \& Olatunji, B. O. (20II). Attentional control in OCD and GAD: Specificity and associations with core cognitive symptoms. Behaviour research and therapy, 49(II), 756-762.

Arntz, A., Voncken, M., \& Goosen, A. C. (2007). Responsibility and obsessive-compulsive disorder: An experimental test. Behaviour research and therapy, 45(3), 425-435.

Aycicegi, A., Dinn, W. M., Harris, C. L., \& Erkmen, H. (2003). Neuropsychological function in obsessive-compulsive disorder: effects of comorbid conditions on task performance. European psychiatry, I8(5), 24I-248.

Baer, R. A. (2003). Mindfulness training as a clinical intervention: A conceptual and empirical review. Clinical psychology: Science and practice, 10(2), 125-143. 
Baer, R. A., Smith, G. T., Hopkins, J., Krietemeyer, J., \& Toney, L. (2006). Using self-report assessment methods to explore facets of mindfulness. Assessment, 13(I), 27-45.

Baer, R. A., Smith, G. T., Lykins, E., Button, D., Krietemeyer, J., Sauer, S., . . W Williams, J. M. G. (2008). Construct validity of the five facet mindfulness questionnaire in meditating and nonmeditating samples. Assessment, 15(3), 329-342.

Bayrami, M., Abad, T. H. N., Ghoradel, J. A., Daneshfar, S., Heshmati, R., \& Moslemifar, M. (2012). The role of positive and negative affectivity, optimism, pessimism, and information processing styles in student psychological adjustment. Procedia-Social and Behavioral Sciences, 46, 306-310.

Bayrami, M., Heshmati, R., \& Karami, R. (20II). Anxiety: Trait/Sate, Sensation Seeking and Marital Satisfaction in Married Women. Procedia-Social and Behavioral Sciences, 30, 765-770.

Clark, D. A. (2004). Cognitive-behavioral therapy for OCD: Guilford Press.

Crowe, K., \& McKay, D. (2016). Mindfulness, obsessive-compulsive symptoms, and executive dysfunction. Cognitive therapy and research, 40(5), 627-644.

Derryberry, D., \& Reed, M. A. (2002). Anxiety-related attentional biases and their regulation by attentional control. Journal of abnormal psychology, II I (2), 225.

Didonna, F., Lanfredi, M., Xodo, E., Ferrari, C., Rossi, R., \& Pedrini, L. (2019). Mindfulness-based Cognitive Therapy for Obsessive-Compulsive Disorder: A Pilot Study. Journal of Psychiatric Practice ${ }^{\circledR}, 25(2)$, I56- 170.

Duncan, B. L., Miller, S. D., Wampold, B. E., \& Hubble, M. A. (2010). The heart and soul of change: Delivering what works in therapy: American Psychological Association.

Emanuel, A. S. (2009). The Role of Mindfulness in Affective Forecasting. Kent State University,

Fineberg, N. A., \& Gale, T. M. (2005). Evidence-based pharmacotherapy of obsessive-compulsive disorder. International Journal of Neuropsychopharmacology, 8(I), 107-I29.

Fresco, D. M., Frankel, A. N., Mennin, D. S., Turk, C. L., \& Heimberg, R. G. (2002). Distinct and overlapping features of rumination and worry: The relationship of cognitive production to negative affective states. Cognitive therapy and research, 26(2), 179-188.

Frewen, P. A., Evans, E. M., Maraj, N., Dozois, D. J., \& Partridge, K. (2008). Letting go: Mindfulness and negative automatic thinking. Cognitive therapy and research, 32(6), 758-774.

Goradel, J. A., Heshmati, R., \& Alilo, M. M. (2012). Personality Dimensions, Emotional Intelligence and Job Burnout in Nurses. Medical Journal of Tabriz University of Medical Sciences \& Health Services, 34(5).

Group, O. C. C. W. (2005). Psychometric validation of the obsessive belief questionnaire and interpretation of intrusions inventory-Part 2: Factor analyses and testing of a brief version. Behaviour research and therapy, 43(II), I527-1542. 
Heshmati, R., Ghorbani, N., Rostami, R., Ahmadi, M., \& Akhavan, H. (2010). Comparative Study of Alexithymia in Patients with Psychotic Disorders, Non Psychotic and Normal People. Scientific Journal of Hamadan University of Medical Sciences and Health Services, I7(I); 56-6I.

Heshmati, R. (2017). Structural Equation Modelling of Alexithymia Determinants: The Role of BAS/BIS and Dispositional Mindfulness. Journal of Research in Psychological Health, 10(4), 3044.

Heshmati, R. (2016). Structural Relationships among Functional Status, Health Beliefs and BMI in Patients with CAD: The Mediator Role of Cardiac Self-Efficacy. Journal of Health and Care, I8(3), 19|-206.

Heshmati, R., Hatami, J., Bahrami, E. H., \& Sadeghian, S. (20/4). The effect of the biological status of CAD patients on health related quality of life: the mediating role of illness representations.Journal of Research In Behavioural Sciences, I2( 3); 328-34I.

Heshmati, R., Allahverdipour, H., Tabatabaei, M. G., \& Kamrani, S. (20II). Toronto Alexithymia Scale (TAS-20): A study of patients with schizophrenia spectrum disorders. Procedia-Social and Behavioral Sciences, 30, 77I-775.

Heshmati, R., \& Ahmadkhanloo, E. (2017). Emotional Intelligence, Emotional Self-regulation and Dispositional Mindfulness in High School Intelligent Students. Mediterranean Journal of Clinical Psychology, 5(2).

Heshmati, R., Gharadaghi, A., Jafari, E., \& Gholizadehgan, M. (2017). Prediction of marital burnout in couples seeking divorce with knowledge of demographic characteristics, mindfulness, and emotional resilience. Family counseling \& psychotherapy, I (23), 22-I.

Heshmati, R., Onari, A. R., \& Shokrallahi, R. (2016). The effectiveness of group play therapy techniques on state anxiety, positive emotions and general compatibility level in special students with learning disabilities. Journal of Learning Disabilities, 5( 4); 7-24.

Heshmati, R., \& Ghorbani, F. (2016). The effect of mindfulness-based stress reduction (MBSR) program on physical functioning and health related quality of life (HRQOL) in people with coronary artery disease (cad). Iranian Journal of Cardiovascular Nursing, 5(3); 16-25.

Joormann, J. (2006). Differential effects of rumination and dysphoria on the inhibition of irrelevant emotional material: Evidence from a negative priming task. Cognitive therapy and research, 30(2), 149-160.

Julien, D., O'Connor, K. P., \& Aardema, F. (2007). Intrusive thoughts, obsessions, and appraisals in obsessive-compulsive disorder: A critical review. Clinical psychology review, 27(3), 366-383.

Kabat-Zinn, J. (2003). Mindfulness-based interventions in context: past, present, and future. Clinical psychology: Science and practice, 10(2), I44-156.

Karami, J., Momeni, K., \& Zakiei, A. (20/3). The relationship alexitymia, positive affect and negative affect with the obsessive-compulsive disorder syndrome. The Journal of Urmia University of Medical Sciences, 24(7), 534-542. 
Key, B. L., Rowa, K., Bieling, P., McCabe, R., \& Pawluk, E. J. (2017). Mindfulness-based cognitive therapy as an augmentation treatment for obsessive-compulsive disorder. Clinical psychology \& psychotherapy, 24(5), II09-II 20.

Landmann, S., Cludius, B., Tuschen-Caffier, B., Moritz, S., \& Külz, A. K. (2019). Mindfulness predicts insight in obsessive-compulsive disorder over and above OC symptoms: An experiencesampling study. Behaviour research and therapy, I2 I, 103449.

Leahy, R. L. (2007). Emotional schemas and self-help: Homework compliance and obsessivecompulsive disorder. Cognitive and Behavioral Practice, I4(3), 297-302.

M, M. A. (2013). comparing the performance of people with obsessive-compulsive disorder, post-traumatic stress disorder in executive functions. . J Psychol, I 7(I).

Moore, A., \& Malinowski, P. (2009). Meditation, mindfulness and cognitive flexibility. Consciousness and cognition, I8(I), I76-I86.

Muller, J., \& Roberts, J. E. (2005). Memory and attention in obsessive-compulsive disorder: a review. Journal of anxiety disorders, 19(1), I-28.

Muris, P., Roelofs, J., Meesters, C., \& Boomsma, P. (2004). Rumination and worry in nonclinical adolescents. Cognitive therapy and research, 28(4), 539-554.

Nolen-Hoeksema, S., Morrow, J., \& Fredrickson, B. L. (1993). Response styles and the duration of episodes of depressed mood. Journal of abnormal psychology, 102(I), 20.

Papageorgiou, C., \& Wells, A. (2004). Depressive rumination: Nature, theory and treatment: Wiley Online Library.

Pashinian, A., Faragian, S., Levi, A., Yeghiyan, M., Gasparyan, K., Weizman, R., . . Poyurovsky, M. (2006). Obsessive-compulsive disorder in bipolar disorder patients with first manic episode. Journal of affective disorders, 94(I-3), I5 I-I56.

Pedersen, S. S., \& Denollet, J. (2003). Type D personality, cardiac events, and impaired quality of life: a review. European journal of cardiovascular prevention \& rehabilitation, I0(4), 24I-248.

Pressman, S. D., \& Cohen, S. (2005). Does positive affect influence health? Psychological bulletin, I3I(6), 925.

Purdon, C., \& Clark, D. A. (1999). Metacognition and obsessions. Clinical Psychology \& Psychotherapy: An International Journal of Theory \& Practice, 6(2), I02-I I0.

Sadock, B. J., \& Sadock, V. A. (20II). Kaplan and Sadock's synopsis of psychiatry: Behavioral sciences/clinical psychiatry: Lippincott Williams \& Wilkins.

Sanavio, E. (1988). Obsessions and compulsions: the Padua Inventory. Behaviour research and therapy, 26(2), 169-177. 
Shaker, A., Heshmati, R., \& Rahimi, M. P. (20I0). Investigation of Marital adjustment in people with secure, preoccupied, dismissing and fearful attachment styles. Procedia-Social and Behavioral Sciences, 5, 1823-1826.

Raj, A., \& Kumar, P. (2019). Efficacy of Mindfulness Based Stress Reduction (MBSR): A Brief Overview. Journal of Disability Management and Rehabilitation, 4(I), 73-8I.

Segerstrom, S. C., Tsao, J. C., Alden, L. E., \& Craske, M. G. (2000). Worry and rumination: Repetitive thought as a concomitant and predictor of negative mood. Cognitive therapy and research, 24(6), 67I-688.

Smith, J. M., \& Alloy, L. B. (2009). A roadmap to rumination: A review of the definition, assessment, and conceptualization of this multifaceted construct. Clinical psychology review, 29(2), II6128.

Spindler, H., Denollet, J., Kruse, C., \& Pedersen, S. S. (2009). Positive affect and negative affect correlate differently with distress and health-related quality of life in patients with cardiac conditions: Validation of the Danish Global Mood Scale. Journal of Psychosomatic Research, 67(I), 57-65.

Watson, D., Clark, L. A., \& Carey, G. (1988). Positive and negative affectivity and their relation to anxiety and depressive disorders. Journal of abnormal psychology, 97(3), 346. 